\title{
Should health care institutions provide job accommodations for health care workers with serious mental health concerns during the COVID-19 pandemic?
}

\author{
Alexandra M. Villagran*1, Janet Malek², Sophie C. Schneider ${ }^{3}$, Christi J. Guerrini ${ }^{2}$ \\ ${ }^{1}$ Baylor College of Medicine, United States \\ ${ }^{2}$ Center for Medical Ethics and Health Policy, Baylor College of Medicine, United States \\ ${ }^{3}$ Menninger Department of Psychiatry and Behavioral Sciences, Baylor College of Medicine, United States
}

Received: September 29, 2020

DOI: $10.5430 /$ jha.v9n5p31
Accepted: October 25, 2020

Online Published: November 9, 2020

\begin{abstract}
As the Coronavirus Disease 2019 pandemic continues, increased attention has been given to its mental health impacts on frontline health care workers. There is a consensus, consistent with established standards applicable to the duty to treat, that health care workers who are especially vulnerable to risk of physical harm should be provided job accommodations to reduce their risk of disease exposure, but it is unclear whether health care workers should be provided similar accommodations if their vulnerability relates specifically to mental health concerns. Especially given emerging evidence that the pandemic is taking a heavy toll on the mental health of health care workers, this issue should be included in policy conversations involving support of health care workers and provision of resources to them during the pandemic. Arguments in favor of expanding accommodations to those with mental health concerns include institutions' ethical duty to protect vulnerable workers and not discriminate against their employees, as well as broader consideration of the consequences of not providing accommodations, both for health care workers and patients.
\end{abstract}

Key Words: Coronavirus, Mental health, Accommodations, Health care , Duty to treat

\section{INTRODUCTION}

During the Coronavirus Disease 2019 (COVID-19) pandemic, there has been much discussion regarding the protection of vulnerable health care workers (HCWs). Many institutions allow for accommodations for HCWs with underlying conditions that increase their risk for severe illness from SARS-CoV-2, the virus that causes COVID-19 disease. ${ }^{[1,2]}$ According to the most recent guidance from the U.S. Centers for Disease Control and Prevention (CDC), high-risk conditions include older age, chronic kidney disease, chronic obstructive pulmonary disease, immunocompromised state, obesity, serious heart conditions, sickle cell disease, and type 2 diabetes. ${ }^{[3]}$ Allowing providers at highest risk for serious COVID-19 disease to receive accommodations is important because although HCWs have an ethical duty to treat patients, health care institutions have a reciprocal duty to protect their

*Correspondence: Alexandra M. Villagran; Email: amvillag@bcm.edu; Address: Baylor College of Medicine, United States. 
most vulnerable workers from harm.

Accommodations offered to those in high-risk groups may include the option not to participate in procedures with high aerosolization risk, the option not to treat patients with confirmed or suspected COVID-19, the option to use telemedicine platforms, the option to transition to administrative work, or the option to use vacation or leave time to step back from clinical work. For example, in March, 2020, the authors' institution adopted a policy stating that employees with direct patient contact who are in CDC-identified high-risk groups may request job modification to decrease their risk of infection. ${ }^{[4]}$ The policy provides that high-risk employees should work with their supervisors to modify their role to lower their risk (e.g., temporarily changing units or transitioning to a non-patient facing role). On April 13, 2020 this policy was updated to reflect changing CDC guidance about underlying conditions that increase risk and to allow qualifying HCWs to request a leave of absence via the standard process. Specifically, it provides that although HCWs' "ethical and professional obligations... [include] provid[ing] care and treatment of patients... regardless of confirmed or suspected diagnosis, including suspected or confirmed COVID-19... [HCWs] need not care for patients at all costs." Therefore, HCWs "may request an accommodation in the treatment of patients with suspected or confirmed COVID-19 if they have a [CDC-identified] medical condition that puts them at increased risk... or their physical disabilities make it more difficult for them to follow precise protocols for staff protection with PPE."

Despite evidence that frontline $\mathrm{HCW}$ mental health is at risk, little attention has been given to the appropriateness of similar accommodations for HCWs at highest risk for mental health harms due to caring for patients with COVID19. ${ }^{5-7]}$ At the authors' institution, access to mental health and wellness services was expanded in response to COVID19 , and these resources are mentioned in accommodation materials. ${ }^{[4,8]}$ However, only specific medical diagnoses and physical disabilities qualify for COVID-19 accommodations. ${ }^{[4]}$

Detailed below are several ethical arguments in favor of mental health accommodations: protection of vulnerable workers, justice in determining qualifying conditions, and consideration of consequences for HCWs and patients. To be sure, there are unique challenges associated with providing mental health accommodations including the determination of qualifying criteria for accommodation, possible exacerbation of frontline HCW shortages, and concerns about stigma and licensure. A case-by-case approach to providing mental health accommodations during the pandemic overcomes a number of these challenges.

\section{MENTAL HEALTH CONCERNS OF FRONT- LINE HCWS DURING THE PANDEMIC}

For some providers, mental health concerns may predate the COVID-19 pandemic. U.S.-based studies have found a higher prevalence of certain mental illnesses among HCWs. While the prevalence of depression is about $7 \%$ in the general population, a study of hospital employed nurses found that $18 \%$ had depressive symptoms, and a meta-analysis of mental health studies involving resident physicians found that $29 \%$ had depression or depressive symptoms. ${ }^{[9,10]}$ Additionally, the rate of suicide in male physicians is 1 to 1.5 times higher than the rate for the general population; for female physicians, it is 2 to 4 times higher. ${ }^{[1,12]}$ Regarding posttraumatic stress disorder (PTSD), the prevalence is estimated to be nearly $15 \%$ among physicians and $14 \%$ among nurses compared to $3 \%-4 \%$ of the general population. ${ }^{[11,12]}$ The incidence is greater for those reporting high on-the-job stress and occupational risk, with emergency department resident physicians and intensive care unit nurses at highest risk. ${ }^{[11-13]}$ Though these numbers are compelling, there is evidence that the true rate of mental illness is even higher than reported due to unique disincentives to reporting diagnoses and receiving treatment, namely stigma and concerns regarding licensure and medical board oversight. ${ }^{[14]}$

Frontline HCW mental health is of even greater concern during major disease outbreaks. Following the severe acute respiratory syndrome (SARS) and Ebola epidemics, HCWs experienced elevated rates of PTSD and other forms of psychological distress. ${ }^{[15]}$ Crucially, negative mental health outcomes of HCWs providing patient care during these epidemics were associated both with individual factors, such as perceived risk of infection and the impact of the disease on loved ones, and organizational factors, including exposure to infected patients and level of practical support. ${ }^{[16]}$

The COVID-19 pandemic is likely taking a similar toll on U.S. HCWs given international trends reported in individual studies and meta-analyses and U.S. physicians' established susceptibilities to burnout. ${ }^{[6,17-19]}$ For example, data from China and elsewhere consistently indicate COVID-19 pandemic-associated elevated mental distress in HCWs, including depressive symptoms, anxiety, insomnia, and symptoms of post-traumatic stress. ${ }^{[17-19]}$ A survey of Chinese HCWs fielded from January 29 to February 3, 2020 found elevated symptoms of depression (50\%), anxiety (45\%), insomnia (34\%), and distress (72\%). ${ }^{[20]}$ Another survey-based study from China, for which responses were collected from February 19 to March 6, 2020, found that doctors and nurses 
had a significantly higher prevalence of insomnia, anxiety, depression, somatization, and obsessive-compulsive symptoms compared to non-HCWs. ${ }^{[21]}$ In a meta-analysis of studies from Asia published before April 17, 2020, pooled prevalence of anxiety, depression, and insomnia were $23 \%, 23 \%$, and 39\%, respectively. ${ }^{[18]}$ In March 2020, Italian HCWs reported elevated symptoms of post-traumatic stress (49\%), depression (25\%), anxiety (20\%), insomnia ( $8 \%$ ), and perceived stress $(22 \%) .{ }^{[22]}$

Some data on U.S. HCWs have begun to emerge, with data from a survey of U.S. university employees in April 2020 demonstrating that those working in a clinical capacity had higher anxiety and lower emotional wellbeing compared to nonclinical workers. ${ }^{[23]}$ A survey of residents and clinical fellows at the same university's training program, who were also surveyed in April 2020, found that trainees exposed to COVID-19 patients reported significantly higher stress, burnout, and anxiety than non-exposed trainees. ${ }^{[24]}$ Both groups reported levels of depression consistent with prior studies of resident physicians, as well as similarly low professional fulfillment from their current clinical activities. Our own study found that HCWs are more likely than non-HCWs to seek mental health treatment for pandemic-related concerns. Specifically, in an online survey of U.S. residents from April 17 to 22, 2020, among those participants who had not participated in pre-pandemic mental health treatment over half $(51 \%)$ of those employed in health care systems reported being very or somewhat likely to seek treatment with a mental health professional to help them address a pandemic-related mental health issue, compared with $22 \%$ of other respondents. ${ }^{[25]}$

Consistent with data from prior pandemics, risk factors for negative mental health impact for HCWs during the COVID19 pandemic include individual and institutional factors. Negative mental health impacts have been more prevalent among women, nurses, those required to quarantine, those diagnosed with an organic disease, those at higher risk of contracting COVID-19, and those with a colleague who is/was hospitalized or who passed away due to COVID-19. ${ }^{[18,20,22]}$ Survey data suggest previously diagnosed mental illness may also be a risk factor for negative mental health impacts. ${ }^{[18,26,27]}$ In a study performed in China from February 25 to March 9, 2020, among outpatients seeking care at a university hospital, $21 \%$ of those with preexisting psychiatric diagnoses reported a deterioration of their mental health condition attributable to the pandemic and $22 \%$ reported disruptions to their routine psychiatric care. ${ }^{[26]}$ HCWs might experience disruptions as a result of limited appointment availability or their own constrained schedules, and are likely to be at similar risk for symptom exacerbation. Indeed, in our U.S. general popula-

Published by Sciedu Press tion survey, among those participants who had participated in pre-pandemic mental health treatment, almost all (95\%) of those who worked in health care systems reported increasing or wanting to increase treatment frequency during the pandemic, compared to $34 \%$ of other respondents. ${ }^{[25]}$ Similarly, $82 \%$ of health workers, but only $33 \%$ of other respondents, were very or somewhat likely to increase treatment frequency post-pandemic.

Potential factors driving increased distress among HCWs during the COVID-19 pandemic are numerous. These include moral distress, which is the internal conflict experienced when one feels the ethically correct action is different than that which they are tasked with doing, and moral injury, which results when one causes or fails to prevent an act of moral transgression. Moral distress and injury may be associated with perceptions of unjust allocation of ventilators or other scarce resources, inability to provide seemingly necessary treatment (e.g., nebulized medications) due to institutional policy and/or concern for virus transmission, and inability to allow families to visit loved ones (in some cases, even at the end of life). ${ }^{[28,29]}$ Elevated levels of distress might also be attributed to working conditions (e.g., PPE shortages, uncomfortable PPE, and long work hours), fears of becoming infected or transmitting the virus to others, and the stress of treating unstable patients with limited evidence to guide decision-making. ${ }^{[16,30]}$

Furthermore, during the COVID-19 pandemic, HCWs are not only being exposed to novel stressors in the workplace, but also outside the workplace. For example, they may experience decreased social support due to choosing to selfisolate for family/friends' protection, as well as stigma and discrimination due to being viewed as an agent of disease transmission. Perhaps surprisingly, large proportions of US and Canadian adults report wanting to avoid HCWs (47\%), believing that HCWs should be isolated from their own families (31\%), and believing that HCWs should not go out in public $(25 \%) .{ }^{[31]}$ The willingness to restrict the freedoms of HCWs and desire for social distance can be expected to greatly reduce the emotional support available to $\mathrm{HCWs}$ outside of work.

\section{ETHICAL ARGUMENTS FOR MENTAL HEALTH ACCOMMODATION POLICIES}

Given the pandemic's persistence, institutions providing accommodations for HCWs at physical health risk should consider similar accommodations for those at risk for exacerbation of serious mental illness and those with significant new psychological symptoms associated with the care of COVID-19 patients. There are three primary ethical argu- 
ments in favor of mental health accommodation policies for HCWs during the pandemic. First, HCWs with mental illness are a vulnerable population deserving protection. Like physical vulnerabilities, mental health vulnerabilities can have life-threatening consequences as demonstrated by reports of recent suicides by HCWs caring for patients with COVID-19. ${ }^{[6,32]}$ If an institution is committed to protecting their most vulnerable HCWs during this pandemic, it should include protections related to mental illness and/or current psychiatric symptoms.

Second, institutions should provide these protections regardless of whether the HCW's specific vulnerability is related to physical or mental health. Many institutions have demonstrated their commitment to vulnerable HCWs by offering job modifications or opt outs for those with documented physical health conditions that increase their risk of infection. There is no basis for privileging physical illness over mental illness given the current understanding of the biopsychosocial roots of each. Indeed, to provide protections for HCWs with physical but not mental illnesses might constitute discrimination, a matter of particular importance given the historical stigmatization and marginalization of mental illness and mental health care.

Third, failure to protect vulnerable HCWs can have negative consequences not only for providers, but also for patients, who could receive suboptimal care if their provider is suffering from serious mental illness. Furthermore, if a HCW is not provided what they see as necessary accommodations, they may consider dropping out of the health care workforce entirely at a time when HCWs are badly needed. ${ }^{[33]}$ Providing accommodations may mitigate these risks over the long term. Additionally, given that the pandemic will likely persist for some time, providing HCWs accommodations for mental health reasons, even if such accommodations take them out of the frontline workforce, may allow them to rejoin the front lines later, thereby benefiting future patients with COVID-19. However, empirical research is needed to fully understand these potential consequences.

It might be argued that a policy allowing HCWs to choose which patients to see or how to engage with certain patients (i.e., through low-risk work or telemedicine) based on a specific diagnosis conflicts with the duty to treat, which is the responsibility of HCWs to provide care for patients even when circumstances put them at increased risk. ${ }^{[34]}$ The concept of duty to treat during infectious disease outbreaks was examined during the acquired immunodeficiency syndrome (AIDS) epidemic in the late 1980s, as physicians weighed their duty to treat patients with AIDS with their own risk of contracting the disease and possibly spreading it to their families. ${ }^{[34,35]}$ The general ethical consensus was that HCWs had a duty to care for patients with AIDS given that the risk of transmission during routine care was relatively low. The duty to treat has been incorporated into the American Medical Association (AMA) Code of Ethics, which states the commitment that physicians have made to care for the sick obligates them to provide care "even in the face of greater than usual risks" to their personal health. ${ }^{[36]}$ Importantly, however, the Code recognizes the need to weigh current duty against the ability to provide care in the future. The American Nurses Association Code of Ethics similarly recognizes a duty to treat, but also that "there may be limits to the personal risk of [emotional, psychological, physical, or spiritual] harm nurses can be expected to accept as an ethical duty."[37] Given that the duty to treat allows exceptions, providing accommodations that prioritize the protection of HCWs is not inconsistent with fulfillment of that duty. Providing accommodations also protects HCWs' ability to provide future care, which is an important consideration in the AMA's articulation of the duty to treat.

During the COVID-19 pandemic, the emerging consensus is that there are limits to the duty to treat, though these are not well defined. ${ }^{[38-42]}$ Following the SARS pandemic, calls were made to elaborate on the scope of the duty to treat and considerations that may override it. ${ }^{[43-45]}$ However, no specific guidelines were put forward by relevant HCW professional bodies. The Hastings Center's ethical framework for COVID-19-related guidelines suggests development of policies and processes concerning HCW refusal to provide care but it does not make recommendations. ${ }^{[38]}$ Some scholars recognize only PPE shortages as an acceptable reason to forgo this duty, but many recognize personal circumstances as sufficient to exempt certain providers. ${ }^{[38-40]}$ As no specific recommendations regarding qualifying personal circumstances are in place, and as duty to treat must be weighed against HCWs' obligations to themselves, their families, and future patients, it would be reasonable to approach the issue of duty to treat during this pandemic on a case-by-case basis $^{[43,44,46]}$ This is, of course, what is already being done at institutions allowing those with CDC-identified high-risk conditions to request accommodations. The same reasoning can be used to justify exemption from the duty to treat for those at high risk for poor mental health outcomes.

\section{Policy implementation}

Duty to treat is associated with a reciprocal duty of society and medical institutions specifically to protect HCWs, particularly those at high risk of harm from providing such treatment. Recognizing that the mental health impact of caring for COVID-19 patients can be significant, institutions are ethically obligated to at least provide HCWs with access 
to mental health resources. This may mean deployment of behavioral health providers as volunteers to provide support, including interventions aimed at prevention (e.g., stress reduction, mindfulness, support groups), crisis support (e.g., hotlines), and treatment (therapy and/or medication). ${ }^{[7]}$ This support is vital not only during the pandemic, but also after it subsides, as evidence from the SARS pandemic indicates that mental health impacts will likely persist for some time. ${ }^{[47,48]}$ Given that HCWs may be hesitant to disclose conditions and seek necessary care and/or accommodation, institutions may also consider offering mental health screenings to all of their employees, with positive screens directing employees to potentially helpful resources. ${ }^{[18]}$ In addition to mental health-specific interventions, other efforts underway to equip HCWs with necessary PPE, provide hazard pay, forgive student loans, and modify shift schedules to accommodate competing obligations when possible may serve as protective factors. These should not, however, be viewed as a substitute for targeted mental health interventions. And for those HCWs with more severe symptoms or at highest risk of poor outcomes, increased support may not be sufficient. Therefore, institutions should go one step further and consider implementing policies during the pandemic to allow HCWs to be provided accommodations, including being relieved of their duty to treat infected patients to address serious mental health concerns initiated or aggravated by those activities.

In implementing or updating any policy, pragmatic considerations are paramount. There are certainly challenges associated with providing mental health accommodations. First, it is unclear which mental illnesses should qualify for accommodation, whereas physical conditions that increase risk of COVID-19 are by now fairly well established. Making condition-specific recommendations may not be feasible given that COVID-related stress may have the potential to exacerbate a wide range of mental disorders, and difficulties in functioning related to specific disorders are highly variable. Evaluations should instead be individualized and might take into account the degree of an individual's distress and functional challenges, known risk factors for severe mental illness or suicidality, the presence of symptoms that may directly compromise a HCW's ability to perform their job duties (such as psychosis or intoxication), and the support or stressors affecting the individual outside of work. Second, some may argue that neither those with mental nor physical health conditions should be exempt from the duty to treat given that certain accommodations could exacerbate the potential shortage of frontline HCWs during a pandemic. As such, decisions about and procedures for mental health accommodations would be made by specific institutions based on local conditions such as illness rates and staffing needs, consistent with the CDC recommendation on accommodation policies for those at high physical risk. ${ }^{[1]}$

Finally, the benefits of mental health accommodations will not be achieved if HCWs with mental illness are unwilling or unable to disclose their qualifying conditions. Given stigma and concerns regarding licensure, HCWs who disclose mental illnesses for the purpose of accommodation must be ensured confidentiality and protection from retaliation. Although most state boards will not intervene unless there is evidence of impairment, some licensure applications ask about hypothetical and past impairment. ${ }^{[49]}$ The intersection of mental health conditions justifying job accommodations and perceived impairment giving rise to licensing board intervention is a complex issue beyond the scope of this paper. Institutional guidance and policies for $\mathrm{HCWs}$ during the COVID-19 pandemic should be designed to encourage rather than discourage them from seeking mental health treatment and/or accommodations.

\section{Conclunsions}

Frontline HCWs are under significant stress due to caring for patients with COVID-19 which may exacerbate existing mental illness or cause significant new mental health symptoms. As many institutions are already providing accommodations for HCWs with physical health vulnerabilities, it is necessary to consider providing similar accommodations for those with mental health vulnerabilities. By providing such accommodations for those with current mental health symptoms or severe mental illness at risk for exacerbation, institutions would uphold their duty to protect vulnerable HCWs and ensure just treatment of employees with mental illness. Furthermore, providing accommodations ultimately may save the lives of providers at risk of serious mental distress and suicide, as well as their future patients.

\section{CONFlicts of InTEREST Disclosure}

The authors declare they have no conflicts of interest. 


\section{REFERENCES}

[1] Centers for Disease Control and Prevention. Clinical Questions about COVID-19: Questions and Answers. [cited 2020 May 19]. Available from: https://www.cdc.gov/coronavirus/2019-ncov/hcp/ faq.html\#COVID-19-Risk

[2] Kofman A, Hernandez-Romieu A. Protect older and vulnerable health care workers from Covid-19. STAT News. 2020 Mar 25 [cited 2020 Apr 16]. Available from: https : //www.statnews. com/2020/03/25/protect-older - and-vulnerable-health-care-workers-from-covid-19/

[3] Centers for Disease Control and Prevention. People Who Are at Higher Risk for Severe Illness. [cited 2020 May 19]. Available from: https://www.cdc.gov/coronavirus/2019-ncov/need -extra-precautions/people-at-higher-risk.html

[4] Incident Command Center BC of M. Direct Patient Contact. 2020 [cited 2020 Apr 25]. Available from: https ://www.bcm.edu/co ronavirus-preparedness/coronavirus-baylor-communi ty/incident-command-center-patient-contact

[5] Taylor WD, Blackford JU. Mental Health Treatment for Front-Line Clinicians During and After the Coronavirus Disease 2019 (COVID19) Pandemic: A Plea to the Medical Community. Ann Intern Med 2020 May. PMid: 32453637. https ://doi .org/10.7326/M20-2 440

[6] Senior J. What One Doctor's Suicide Taught Us. The New York Times. 2020 May 3 [cited 2020 Jul 29]. Available from: https://www.nytimes.com/2020/05/03/opinion/cor onavirus-doctors-mental-health.html

[7] Gold J. The Covid-19 crisis too few are talking about: health care workers' mental health. STAT News. 2020 Apr 3 [cited 2020 Apr 23]. Available from: https://www.statnews.com/2020/04/0 3/the-covid-19-crisis-too-few-are-talking-about-h ealth-care-workers-mental-health/

[8] Medicine BC of Coronavirus Wellness Resources. [cited 2020 Sep 27]. Available from: https://www.bcm.edu/coronavirus/fo $r$-learners-and-educators/wellness-resources

[9] Letvak S, Ruhm CJ, McCoy T. Depression in Hospital-Employed Nurses. Clin Nurse Spec. 2012 May; 26(3): 177-82 [cited 2020 Apr 29]. PMid: 22504476. https ://doi.org/10.1097/NUR. Ob013e 3182503efo

[10] Mata DA, Ramos MA, Bansal N, et al. Prevalence of depression and depressive symptoms among resident physicians a systematic review and meta-analysis. JAMA. 2015 Dec 8; 314(22): 2373-83. PMid: 26647259. https://doi.org/10.1001/jama.2015.15845

[11] Sendler DJ, Rutkowska A, Makara-Studzinska M. How the exposure to trauma has hindered physicians' capacity to heal: prevalence of PTSD among healthcare workers. Eur. J. Psychiat. 2016.

[12] Mealer ML, Shelton A, Berg B, et al. Increased prevalence of posttraumatic stress disorder symptoms in critical care nurses. Am J Respir Crit Care Med. 2007; 175(7): 693-7. PMid: 17185650. https://doi.org/10.1164/rccm.200606-7350C

[13] Vanyo L, Sorge R, Chen A, et al. Posttraumatic Stress Disorder in Emergency Medicine Residents. Ann Emerg Med. 2017; 70(6): 898-903. PMid: 28826753. https://doi.org/10.1016/j.anne mergmed.2017.07.010

[14] Hendin H, Reynolds C, Fox D, et al. Licensing And Physician Mental Health: Problems And Possibilities. J Med Licens Discip. 2007; 93(2).

[15] Brooks SK, Dunn R, Amlôt R, et al. A Systematic, Thematic Review of Social and Occupational Factors Associated with Psychological Outcomes in Healthcare Employees during an Infectious Disease Outbreak. J Occup Environ Med. 2018; 60(3): 248-57. PMid: 29252922. https://doi.org/10.1097/J0M.0000000000001235
[16] Kisely S, Warren N, McMahon L, et al. Occurrence, prevention, and management of the psychological effects of emerging virus outbreaks on healthcare workers: rapid review and meta-analysis. BMJ. 2020 May 5; 369: m1642. PMid: 32371466. https ://doi.org/10.1 $136 / \mathrm{bmj} \cdot \mathrm{m} 1642$

[17] Luo M, Guo L, Yu M, et al. The psychological and mental impact of coronavirus disease 2019 (COVID-19) on medical staff and general public - A systematic review and meta-analysis. Psychiatry Res. 2020; 291(April): 113190. PMid: 32563745. https : //doi.org/10.1016/j.psychres.2020.113190

[18] Pappa S, Ntella V, Giannakas T, et al. Prevalence of depression, anxiety, and insomnia among healthcare workers during the COVID-19 pandemic: A systematic review and meta-analysis. Brain Behav Immun. 2020; 88: 901-7. PMid: 32437915. https ://doi .org/10.1 016/j.bbi.2020.05.026

[19] Vindegaard N, Benros ME. COVID-19 pandemic and mental health consequences: Systematic review of the current evidence. Brain Behav Immun. 2020; 88. PMid: 32485289. https ://doi .org/10.1 016/j.bbi.2020.05.048

[20] Lai J, Ma S, Wang Y, et al. Factors Associated With Mental Health Outcomes Among Health Care Workers Exposed to Coronavirus Disease 2019. JAMA Netw Open. 2020 Mar 2; 3(3): e203976. PMid: 32202646. https://doi.org/10.1001/jamanetworkopen. 20 20.3976

[21] Zhang WR, Wang K, Yin L, et al. Mental Health and Psychosocial Problems of Medical Health Workers during the COVID-19 Epidemic in China. Psychother Psychosom. 2020; 89(4): 242-50. PMid: 32272480. https://doi.org/10.1159/000507639

[22] Rossi R, Socci V, Pacitti F, et al. Mental Health Outcomes Among Frontline and Second-Line Health Care Workers During the Coronavirus Disease 2019 (COVID-19) Pandemic in Italy. JAMA Netw Open. 2020;3(5): e2010185. PMid: 32463467. https : //doi .org/ 10.1001/jamanetworkopen.2020.10185

[23] Evanoff BA, Strickland JR, Marie Dale A, et al. Work-Related and Personal Factors Associated With Mental Well-Being During the COVID-19 Response: Survey of Health Care and Other Workers. J Med Internet Res. 2020; 22(8). PMid: 32763891. https : //doi.org/10.2196/21366

[24] Kannampallil TG, Goss CW, Evanoff BA, et al. Exposure to COVID19 patients increases physician trainee stress and burnout. Murakami M, editor. PLoS One. 2020; 15(8): e0237301. PMid: 32760131. https ://doi.org/10.1371/journal.pone.0237301

[25] Guerrini CJ, Storch EA, McGuire AL. Essential, not peripheral: Addressing health care workers' mental health concerns during the COVID-19 pandemic. J Occup Heal.

[26] Zhou J, Liu L, Xue P, et al. Mental Health Response to the COVID19 Outbreak in China. Am J Psychiatry. 2020 Jul 1; 177(7): 574-5. PMid: 32375540. https://doi.org/10.1176/appi.ajp. 2020. 20030304

[27] Fernández-Aranda F, Casas M, Claes L, et al. COVID-19 and implications for eating disorders. Eur Eat Disord Rev. 2020; 28: 239-45. PMid: 32346977. https : //doi.org/10.1002/erv. 2738

[28] Borges LM, Barnes SM, Farnsworth JK, et al. A Commentary on Moral Injury Among Health Care Providers During the COVID-19 Pandemic. Psychol Trauma Theory, Res Pract Policy. 2020; 12(S1): S138. PMid: 32496101. https://doi.org/10.1037/tra00006 98

[29] Khoo EJ, Lantos JD. Lessons learned from the COVID-19 pandemic. Acta Paediatr. 2020 Jul 29; 109(7): 1323-5. PMid: 32289175 https://doi.org/10.1111/apa.15307

[30] Liu Q, Luo D, Haase JE, et al. The experiences of health-care providers during the COVID-19 crisis in China: a qualitative study. 
Lancet Glob Heal. 2020 Jun 1; 8(6): e790-8. https://doi.org/ 10.1016/S2214-109X (20) 30204-7

[31] Taylor S, Landry CA, Rachor GS, et al. Fear and avoidance of healthcare workers: An important, under-recognized form of stigmatization during the COVID-19 pandemic. J Anxiety Disord. 2020 Oct 1; 75: 102289. PMid: 32853884 . https://doi.org/10.1016/j.janx dis. 2020.102289

[32] Dean W. Health care worker suicides hint at Covid-19 mental health crisis to come. STAT News. 2020 Apr 30 [cited 2020 May 5]. Available from: https://www.statnews.com/2020/04/30/su icides-two-health-care-workers-hint-at-covid-19-m ental-health-crisis-to-come/

[33] Irshad M, Khattak SA, Hassan MM, et al. How perceived threat of Covid-19 causes turnover intention among Pakistani nurses: A moderation and mediation analysis. Int J Ment Health Nurs. 2020. PMid: 32779356. https://doi.org/10.1111/inm.12775

[34] Geraghty D. Aids and the physician's duty to treat. J Leg Med. 1989; 10(1): 47-58. PMid: 2708907. https://doi.org/10.1080/0194 7648909513560

[35] Daniels N. Duty to treat or right to refuse? Hastings Cent Rep. 1991; 21(2). https://doi.org/10.2307/3562338

[36] Association AM. Physicians' Responsibilities in Disaster Response \& Preparedness. [cited 2020 Apr 14]. Available from: https ://ww w. ama-assn.org/delivering-care/ethics/physicians-r esponsibilities-disaster-response-preparedness

[37] ANA Center for Ethics and Human Rights. American Nurses Association Position Statement on Risk and Responsibility in Providing Nursing Care. Am Nurses Assoc. 2015;

[38] Berlinger N, Wynia M, Powell T, et al. Ethical Framework for Health Care Institutions \& Guidelines for Institutional Ethics Services Responding to the Coronavirus Pandemic. Hast Cent. 2020 [cited 2020 Apr 18]. Available from: https://www. thehastingscenter.or g/ethicalframeworkcovid19/

[39] Force PC-19 T. COVID-19 Ethics Analysis: What is the Ethical Duty of Health Care Workers to Provide Care During COVID-19 Pandemic? 2020.
[40] Bakewell F, Pauls MA, Migneault D. Ethical considerations of the duty to care and physician safety in the COVID-19 pandemic. Can J Emerg Med. 2020. PMid: 32326998. https://doi.org/10.101 $7 /$ cem. 2020.376

[41] Geppert CM. The Duty to Care and Its Exceptions. Fed Pract. 2020.

[42] Kramer JB, Brown DE, Kopar PK. Ethics in the Time of Coronavirus: Recommendations in the COVID-19 Pandemic. J Am Coll Surg. 2020: 1114-8. PMid: 32278728. https://doi.org/10.1016/j . jamcollsurg.2020.04.004

[43] Ruderman C, Tracy CS, Bensimon CM, et al. On pandemics and the duty to care: Whose duty? Who cares? BMC Medical Ethics. BioMed Central. 2006 [cited 2020 Apr 25]. Available from: http://bmcmedethics.biomedcentral.com/art icles/10.1186/1472-6939-7-5

[44] Clark CC. In harm's way: AMA physicians and the duty to treat. J Med Philos. 2005; 30(1): 65-87. PMid: 15814368. https://doi. org/10.1080/03605310590907066

[45] Olick RS. Ethics, epidemics, and the duty to treat. J Public Heal Manag Pract. 2004; 10(4): 21. PMid: 15235383. https://doi.or g/10.1097/00124784-200407000-00013

[46] Malm H, May T, Francis LP, et al. Ethics, pandemics, and the duty to treat. Am J Bioeth. 2008; 8(8): 4-19. PMid: 18802849. https://doi.org/10.1080/15265160802317974

[47] Lung FW, Lu YC, Chang YY, et al. Mental symptoms in different health professionals during the SARS attack: A Follow-up study. Psychiatr Q. 2009 Jun; 80(2): 107-16. PMid: 19247834. https://doi.org/10.1007/s11126-009-9095-5

[48] Liu X, Kakade M, Fuller CJ, et al. Depression after exposure to stressful events: Lessons learned from the severe acute respiratory syndrome epidemic. Compr Psychiatry. 2012 Jan; 53(1): 1523. PMid: 21489421 . https ://doi.org/10.1016/j.comppsyc h. 2011.02 .003

[49] Jones JTR, North CS, Vogel-Scibilia S, et al. Medical licensure questions about mental illness and compliance with the americans with disabilities act. J Am Acad Psychiatry Law. 2018; 46(4): 458-71. 